\title{
A Longitudinal Study of Lameness Incidence and Association with Animal-Based Welfare Measures in Dairy Cows
}

\author{
Mohammed Babatunde Sadiq ${ }^{1}$, Siti Zubaidah Ramanoon ${ }^{1,4 *}$, Wan Mastura \\ Shaik Mossadeq ${ }^{2}$, Rozaihan Mansor ${ }^{3,4}$ and Sharifah Salmah Syed-Hussain ${ }^{3}$ \\ ${ }^{1}$ Department of Farm and Exotic Animal Medicine and Surgery, Faculty of Veterinary Medicine, Universiti \\ Putra Malaysia, 43400 UPM Serdang, Malaysia \\ ${ }^{2}$ Department of Veterinary Pre-Clinical Sciences, Faculty of Veterinary Medicine, Universiti Putra Malaysia, \\ 43400 UPM Serdang, Malaysia \\ ${ }^{3}$ Department of Veterinary Clinical Studies, Faculty of Veterinary Medicine, Universiti Putra Malaysia, \\ 43400 UPM Serdang, Malaysia \\ ${ }^{4}$ Centre of Excellence (Ruminant), Faculty of Veterinary Medicine, Universiti Putra Malaysia, \\ 43400 UPM Serdang, Malaysia
}

\section{ABSTRACT}

The objective of this study was to investigate time to lameness event, prevalence of claw lesions, and their associations with animal-based welfare measures (ABWMs) in dairy cows. A total of 120 non-lame lactating cows ( $n=30$ each from four intensive dairy farms) having no claw lesion were enrolled in the study. The cow-level enrollment criteria included good body condition score (BCS), normal hock condition score, absence of body injuries, and normal claw length. Information on cows' parity, milk yield, and previous lameness event (PLE) were recorded. The cows were observed twice monthly (every 2 weeks) for locomotion scores (LS), and ABWMs, whereas claw lesions were recorded upon onset of lameness and at the end of the observation period. Cows were considered lame when 2 consecutive $\mathrm{LS}=3$, or any assessment with score 4 . Cox regression models were used to investigate lameness incidence and the association with ABWMs, while association between

ARTICLE INFO

\section{Article history:}

Received: 17 April 2020

Accepted: 01 September 2020

Published: 24 February 2021

DOI: https://doi.org/10.47836/pjtas.44.1.03

$\overline{\text { E-mail addresses: }}$

Sadiquemohammed99@yahoo.com

(Mohammed Babatunde Sadiq)

sramanoon@upm.edu.my (Siti Zubaidah Ramanoon)

wmastura@upm.edu.my (Wan Mastura Shaik Mossadeq)

rozaihan@upm.edu.my (Rozaihan Mansor)

sharifahsalmah@gmail.com (Sharifah Salmah Syed-Hussein)

* Corresponding author the latter and claw horn lesions (CHL) prevalence were analyzed using logistic regression models. Twenty-four percent $(29 / 120)$ of the cows were lame during the study period. Lameness risk was associated with PLE (Hazard ratio; HR $=7.4 ; 95 \%$ CI 2.4-23.0), presence of overgrown claw $(\mathrm{HR}=3.7 ; 95 \%$ CI 1.1-12.6) and low BCS pre-lame $(\mathrm{HR}=4.5 ; 95 \%$ CI 1.3-16.6). Amongst the cows affected with claw 
lesions, $68.4 \%$ (37/44) were lame and CHL were predominant $(75.4 \%)$ compared to infectious claw lesions $(24.7 \%)$. Cows with lower $\mathrm{BCS}(<3.0)(\mathrm{OR}=5.7 ; 95 \% \mathrm{CI} 1.6$ 20.4) and those with PLE (OR $=7.2 ; 95 \% \mathrm{CI}$ 2.1-24.7) were more likely to have CHL. Management practices such as maintaining cows' body condition, improved care for those with history of lameness, and proper claw trimming could assist farmers to reduce lameness incidence in the studied herds.

Keywords: Claw lesions, claw trimming, dairy cows, lameness, welfare

\section{INTRODUCTION}

Lameness is an important health problem in dairy cows (Cook et al., 2016). Lameness is also a major animal welfare issue due to the manifestation of pain and behavior changes in affected cows (Ramanoon et al., 2018b; Thomas et al., 2016). The condition continues to be the cause of economic losses to farmers resulting from reduced milk yield (Green et al., 2014; Sadiq et al., 2019), maintenance and treatment of affected cows and higher culling risk (Charfeddine \& Cabral-Perez, 2017).

Claw lesions are responsible for most locomotion disorders in dairy herds (Bryan et al., 2012; Sadiq et al., 2017a). The prevalence of lesions causing lameness varies under different management systems, with intensively managed dairy cows experiencing higher lameness prevalence compared to pasture-based systems (Hund et al., 2019). However, the risk factors for lameness and specific claw lesions on intensively managed dairies are multifaceted at cow and herd levels (Olechnowicz et al., 2010; Sadiq et al., 2017b; Solano et al., 2015). For instance, the development of claw horn lesions (CHL) has been linked to the overloading on softer regions of the lateral hind claws, due to disproportionate heel height between the medial and lateral claws, biomechanical reaction at the floorclaw interface (Nuss \& Paulus, 2006), and peri-calving metabolic and hormonal changes leading to negative energy balance (Lim et al., 2015; Newsome et al., 2017a). For infectious claw lesions (ICL), factors such as presence of an infected cattle, poor leg hygiene, and biosecurity issues have been reported to increase the prevalence of digital dermatitis (DD) and other related lesions in dairy herds (Oliveira et al., 2017; Relun et al., 2013).

Animal-based welfare measures (ABWMs) are vital parameters in assessing the well-being and performance of dairy cows (Robichaud et al, 2019). They include, but not limited to factors such as hock and body condition, leg hygiene, lying behavior, social grooming, and body injuries (Ramanoon et al., 2018b; Sadiq et al., 2017b). These factors have been associated with lameness and specific claw lesions prevalence on dairies (Bran et al., 2018; Solano et al., 2015). Cows with low body condition score (BCS), poor leg hygiene, and hock injuries had greater odds of being lame (Sadiq et al. 2017a; Solano et al., 2015). Likewise, the risk for CHL increased in thin cows and they were more susceptible to future lameness event. (Randall et al., 2015). However, majority of the research 
were cross-sectional; hence, the direction of the relationship between lameness and welfare parameters could not be elucidated.

Lameness and claw lesions are major health and welfare issues in Malaysian dairy herds (Sadiq et al., 2017a, 2020a). Recent studies conducted in dairy farms in Peninsular Malaysia reported lameness and claw lesions prevalence of $33 \%$ and $46 \%$, respectively (Sadiq et al., 2020a, 2021). The associations between cowlevel risk factors and lameness prevalence depicted poor animal welfare (Sadiq et al., 2017a, 2020a). Moreover, only a few farms practiced routine claw trimming (CT) as a lameness management strategy. Lack of claw trimming and hoof care contributed to the high prevalence of overgrown claws and CHL in dairy cows in Peninsular Malaysia (Ramanoon et al., 2018a, Sadiq et al., 2021).

To gain more knowledge on the welfare indicators of lameness risk at cow level and the direction of the events, there is a need for a longitudinal assessment of dairy cows from their non-lame to lameness status. The objective of this study was to determine the time-related changes of animal-based welfare indicators and risk of new lameness event in dairy cows.

\section{MATERIALS AND METHODS}

\section{Study Design and Herd Selection}

Farms were recruited from the list and contacts of dairy farms registered with the Department of Veterinary Services (DVS), Selangor, Malaysia. The inclusion criteria included location of farm within Selangor State in Malaysia, free-stall housing, adequate farm records on animal health, milk yield and fertility, herd size of 50 or more milking cows, periodic trimming of the cows either at dry-off or during lactation, and absence of pasture grazing. A total of 18 farms were contacted and 6 of them agreed to participate in the study. Upon further examination, 2 farms were excluded based on the floor design, management routine during calving, and uncertainty of the cows remaining in the study for the planned period. The factors considered for the management and herd characteristics of the enrolled farms are presented in Table 1. The farms were located in Batang Kali $(n=1)$, Semenyih $(n=2)$, and Kajang $(n=$ 1) while the herd size ranged from $145-200$ cows (mean of 172 cows). All the enrolled cows were Australian Friesian Sahiwal (crossbreed) and the average 305-day milk yield ranged from 2, 700 to $3,200 \mathrm{~kg}$.

\section{Lameness Control}

All the farms practiced routine claw trimming either during dry off or mid-lactation and footbathing as herd health programs targeted to improve claw health. The farmers were informed about the methodology of the study, and that no interruption of routine farm and management practices would be attempted except the suspension of CT in the sampled cows during the study period.

\section{Cow Enrollment}

Information on animal health status, DIM, parity and previous lameness event (PLE) were obtained from each farms' health and production records. Next, all the 
Table 1

Herd characteristics of the studied farms

\begin{tabular}{|c|c|c|c|c|}
\hline Features & Farm 1 & Farm 2 & Farm 3 & Farm 4 \\
\hline Location & Semenyih & Batang Kali & Semenyih & Kajang \\
\hline Herd size & 145 & 170 & 175 & 200 \\
\hline No. of milking cows & 63 & 68 & 85 & 74 \\
\hline $\begin{array}{l}\text { 305-day milk } \\
\text { yield(kg/cow) }\end{array}$ & 3100 & 2700 & 2900 & 3200 \\
\hline \multicolumn{5}{|l|}{ Management system } \\
\hline Housing & Free-stall & Free-stall & Free-stall & Free-stall \\
\hline Access to pasture & No & No & No & No \\
\hline $\begin{array}{l}\text { Stocking rate(cow/ } \\
\text { stall) }\end{array}$ & One & One & One & One \\
\hline \multicolumn{5}{|l|}{ Floor and stall design } \\
\hline Floor type & Concrete & Concrete & Concrete & Concrete \\
\hline Stall base & Rubber mats & Rubber mats & - & - \\
\hline Location & $\begin{array}{l}\text { Milking, walking alley } \\
\text { and resting barn }\end{array}$ & $\begin{array}{l}\text { Milking parlour and } \\
\text { resting barn }\end{array}$ & Resting barn & Resting barn \\
\hline $\begin{array}{l}\text { Frequency of } \\
\text { cleaning } \\
\text { (per day) }\end{array}$ & 2 & 3 & 3 & $>3$ \\
\hline Use of footbath & Yes & Yes & Yes & Yes \\
\hline $\begin{array}{l}\text { Claw trimming } \\
\text { (per year) }\end{array}$ & Once & Once & Twice & Once \\
\hline
\end{tabular}

lactating cows in each herd were assessed for locomotion score (LS) using the fourpoint LS system developed by DairyCo (n. d.). Briefly, the LS system entailed the observation of postural (head bob and back presentation) and gait (stride length, steps, weight transfer or bearing) features during cows' locomotion, which were then aggregated to classify lameness severity. Based on the scale, LS $1=$ sound cows; absence of head bob, straight back presentation, symmetrical gait, and normal stride, LS 2 = non-lame; absence of head bob and/or ached back and shortened stride length, LS 3 = lame; Presence of head bob and/or ached back and shortened stride length, LS 4 = severely lame; as presented in
LS 3 and non-weight bearing or recumbent. Only the non-lame cows that were within 40 days in milk (DIM) and apparently free from other disease conditions were selected for further evaluation. Priority was given to the animals expected to remain in the herd for the study period.

The hind limbs were examined for hock condition score (HCS) on a 3-point scale where, 1 = normal area with no alopecia and inflammation, $2=$ hair loss but absence or slight swelling $(<1-2 \mathrm{~cm}), 3=$ hair loss and substantial swelling $(>2 \mathrm{~cm}$ ) (Cook, 2006). Cows with the two latter scores were not enrolled. Upon hoof examination, only the cows without lesions were enrolled; however, cows with history of PLE or claw 
lesions (one month before study period) were only considered for enrollment after complete recovery from lameness and resolution of lesions. The latter was defined by the presence of LS 1 and non-withdrawal of the previously affected limb/claw upon applying pressure using a hoof tester. The dorsal wall angle was used to measure the presence of claw overgrowth on the hind feet as described by Solano et al. (2015). Values $<45$ degree were classified as overgrown and such cows were not considered for enrollment.

Other ABWMs such as body condition score (BCS), body injuries (BDI), and leg hygiene were recorded during cow enrollment. The BCS was measured using a 4-point scale recorded as thin, poor, moderate and fat respectively (Elanco Animal Health, 1997). Cows with BCS of 3 were enrolled for the study. Presence of injuries on body regions (neck, brisket, carpal joint area, rib-cage area, area over the tuber coxae, ischial area, hock joint area, teats, and udder) was observed as described by Cook et al. (2016). The signs considered as indicators of BDI included presence of external wounds, ulcerations, swellings, localized hair loss, scars, and skin hyperkeratosis. The lateral lower hind limbs were assessed for cleanliness from the coronary band to the tarsal joint region based on degree of manure contamination using a 0-3 scale: $0=$ fresh manure for $<50 \%$ of the area; $1=$ fresh manure for $>50 \%$ of the area; $2=$ dried caked and fresh manure for $<50 \%$ of the area; and $3=$ entire area with dried caked manure (Gibbons et al., 2012). Finally, a purposive sample of 30 Australian Friesian Sahiwal cows were selected from each farm (total $=120$ ) and their tag numbers were recorded. The cows were enrolled at early-lactation and followed for 9 months.

\section{Locomotion Scoring and Cow Characteristics}

One investigator visited the farms twice every month for locomotion scoring of the cows and collection of animal-based data. The locomotion scoring took place immediately after the cows were enrolled until the dry-off period. Two successive LS 3 or a single LS 4 was necessary for a cow to be considered lame as described by Thomas et al. (2016). Immediately a cow fulfilled the lameness definition (censored), lactation stage and DIM were recorded, and all the front and rear feet were examined for claw lesions or other definite cause of lameness.

\section{Assessment of Claw Health and Lesions Recording}

Claw lesions were recorded based on the description of previous authors (Green et al., 2014; Solano et al., 2016) and in conjunction with the International Committee of Animal Recording (ICAR) Claw Health Atlas (Egger-Danner et al., 2015). Infectious lesions consisted of digital dermatitis (DD), heel horn erosion, and swelling of the coronet area (SC), whereas non-infectious group included sole lesions (haemorrhage, ulcer, bruises, and double sole), toe ulcer, white line disease (WLD), heel lesions, (HL). Lesions such as wall fissures, interdigital 
hyperplasia and corkscrew were recorded as "others". The presence of different lesions on a single foot or different feet was considered as multiple lesions, whereas the presence of more than one of the same lesion on one foot or two feet was recorded as a single lesion.

\section{Management of Dropout and Missing Data}

The cows that became lame during the study were managed according to the farms' protocol. Locomotion scores and animal-based data were collected from all the enrolled animals at 18 different time points (every two weeks for 9 months). All the enrolled cows $(n=120)$ remained in the study throughout the study period.

\section{Statistical Analysis}

Descriptive statistics was used to summarize the proportion of lame cows and distribution of claw lesions. To determine the association between ABWMs and lameness occurrence, a multivariable cox proportional regression model was built following a two-stage procedure. Parity and PLE were recorded as present during enrollment. Since similar BCS, HCS, leg hygiene, and claw length were considered before cow enrollment from each farm, the last record of each parameter before the occurrence of two consistent lame scores (LS3 or LS4) was recorded for the affected cows. For the nonlame cows, median scores of each parameter were computed. Next, a univariable cox proportional regression model was constructed to evaluate the association between lameness and the covariates: leg hygiene (clean, dirty, and very dirty), parity, HCS (normal, hair loss, and swelling/ulcer), BCS (thin, good, and fat), BDI (present or absent), claw overgrowth (present or absent), PLE (present or absent), and claw lesion (present or absent). In the next stage, factors were introduced into the multivariable cox proportional regression model if the $p$-value $<0.10$. Farm was introduced into the model as a random effect. A forward method was applied and changes in the remaining coefficients were checked as factors were excluded in the model. $P$-value $<0.05$ was used for the final model.

For lesions prevalence, the outcome was the odds for claw lesion at the end of the follow-up period. Binary logistic regression model was only conducted for ICL as the prevalence of other lesions was relatively small. As such, analysis was done for cows with CHL compared with those without lesions. The final records of the welfare parameters (BDI, HCS, BCS, leg hygiene, and claw length) were used for the analysis, whereas parity and PLE were recorded as present during enrollment. A binary logistic regression model similar two step model building process described earlier was used to build the final multivariable logistic regression models. Comparisons between the predicted proportions in the model and the actual proportions in the data set were used in determining the model fit. The results were presented in odds ratios and at $95 \%$ confidence interval $(\mathrm{CI})$. 
RESULTS AND DISCUSSION

Descriptive Statistics and Characteristic of the Study Population

This work investigated the association between ABWM, lameness occurrence, and claws lesions prevalence in dairy cows. One reason for this piece of work was to elucidate the direction of event between welfare measures such as BCS, body injuries, hock condition, claw length, and the lameness incidence during lactation in the dairy cow. The descriptive statistics for the enrolled cows is presented in Table 2. Fifty-two percent $(63 / 120)$ of the cows were within first 30 DIM, and majority (85\%; $102 / 120$ ) of them had moderate BCS during enrollment. The mean ( \pm SD) milk yield of the sampled cows was $14.3 \pm 1.7 \mathrm{~kg} /$ day and all of them were having normal HCS, claw length, and absence of BDI when they were enrolled.

Table 2

Descriptive statistics of the 120 cows enrolled from the 4 studied farms

\begin{tabular}{|c|c|c|}
\hline Factors & Frequency & $\%$ \\
\hline \multicolumn{3}{|l|}{ DIM } \\
\hline $1-30$ & 63 & 52.5 \\
\hline $31-60$ & 57 & 47.5 \\
\hline \multicolumn{3}{|l|}{ Parity } \\
\hline Primiparous & 41 & 34.2 \\
\hline Second & 47 & 39.2 \\
\hline Third and above & 32 & 26.6 \\
\hline \multicolumn{3}{|l|}{ BCS } \\
\hline 3.0 & 102 & 85 \\
\hline$>3.0$ & 18 & 15 \\
\hline \multicolumn{3}{|l|}{ Body injuries } \\
\hline Normal (absent) & 120 & 100 \\
\hline \multicolumn{3}{|l|}{ Previous lameness event } \\
\hline Yes & 27 & 77.5 \\
\hline No & 93 & 22.5 \\
\hline \multicolumn{3}{|l|}{ Leg hygiene } \\
\hline Clean & 75 & 62.5 \\
\hline Dirty & 35 & 29.2 \\
\hline Very dirty & 10 & 8.3 \\
\hline \multicolumn{3}{|l|}{ HCS } \\
\hline Normal & 120 & 100 \\
\hline \multicolumn{3}{|l|}{ Claw length (all claws) } \\
\hline Normal $\left(\geq 45^{\circ}\right)$ & 120 & 100 \\
\hline Milk yield (kg)/cow/day ${ }^{2}$ & $14.3 \pm 1.7$ & \\
\hline
\end{tabular}

Note. ${ }^{1} \mathrm{DIM}=$ days in milk, ${ }^{2}$ Milk yield is presented in mean \pm standard deviation. Other variables are presented in categories and proportions 


\section{Lameness Incidence and Association} with ABWMs

Twenty-four percent (29/120) of the cows were lame during the study period. At every monthly observation period, the proportion of non-lame cows never went below $60 \%$. The incidence of lameness (24.2\%) reported in the present study was higher than that of Bryan et al. (2012), similar to that of Olechnowicz et al. (2010), but lower compared to that of Green et al. (2014). The difference might be related to the definition of lameness, potential risk factors, and variation in milk yield during lactation. Since the absence of overgrown claw was one of the enrollment criteria, the higher proportion of sound cows might be related to benefits of proper claw length and maintenance of sole thickness. These events improve weight distribution between the medial and lateral hind claws, and frictional properties at the floor-claw interface (Nuss \& Paulus, 2006; Sadiq et al., 2020b; van der Tol et al., 2004).

The factors in the univariable cox regression model included BCS pre-lame, claw length, and PLE. Cows with overgrown claw (Hazard ratio; $\mathrm{HR}=3.4 ; 95 \% \mathrm{CI}$ 1.2-11.4) had higher risk of being lame compared to those with normal claw length. Higher risk for lameness was observed in cows with PLE (HR $=6.9$; 95\% CI 2.323.2) than those without lameness history in previous lactations (Table 3 ). BCS pre-lame was associated ( $p=0.03$ ) with the lameness incidence in the study population. Other factors such as parity, HCS, leg hygiene, and DIM (during enrollment) were not associated with lameness incidence. Similar proportions (44\%) of the cows became lame around early (within 120 DIM) and midlactation (181-200 DIM), while less than $15 \%$ of the lameness cases occurred during late lactation (above 200 DIM) (Figure 1). The predictors of lameness in the final cox regression model were claw length, BCS pre-lame, and previous lameness event. Cow with PLE were 7 times more likely (95\% CI 2.4-23.0) to be lame during the study period compared to those without PLE. Likewise, those with overgrown claw (HR $=3.7 ; 95 \%$ CI 1.1-12.6) and thin BCS pre-lame (HR = 4.5; 95\% CI 1.3-16.6) were at higher risk of being lame than those with normal claw

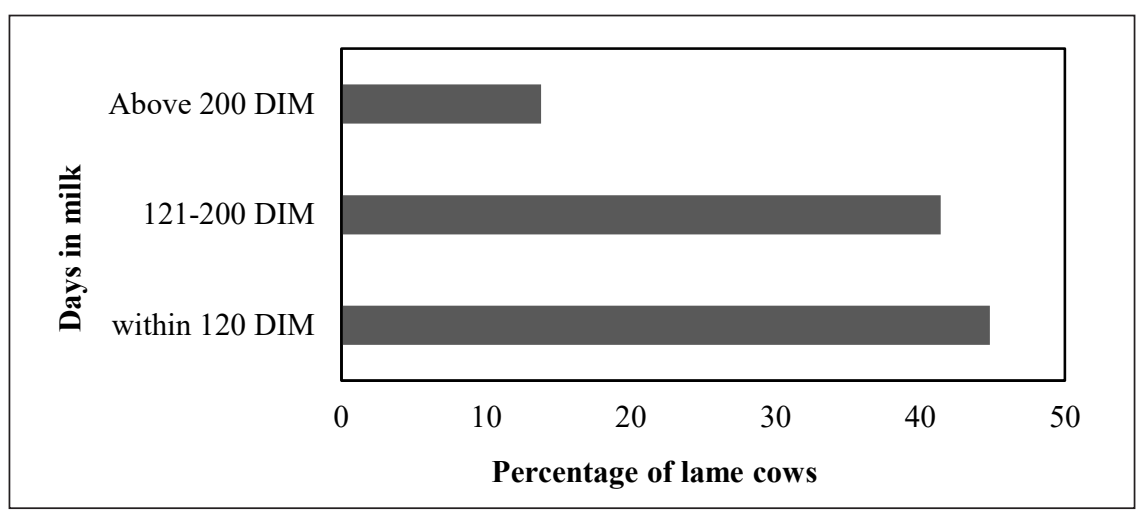

Figure 1. Percentage of lame cows during various stages of lactation 
Association between Lameness Incidence and Animal-based Welfare Measures

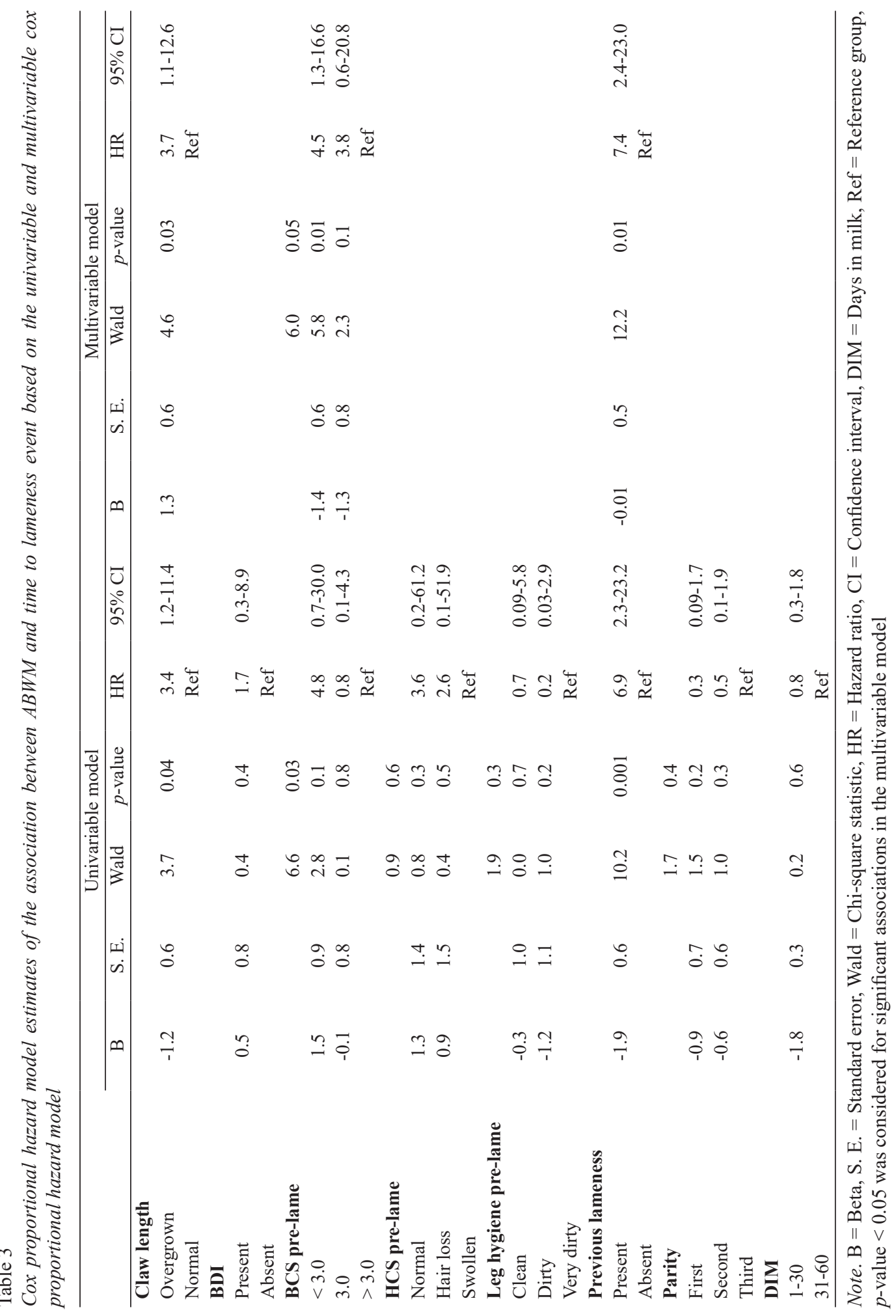

Pertanika J. Trop. Agric. Sci. 44 (1): 49 - 67 (2021) 
length and good body condition $(\mathrm{BCS}=3)$, respectively.

Previous studies have demonstrated positive association between overgrown claw and lameness occurrence in dairy cows (Sadiq et al., 2017a; Solano et al., 2015). Accordingly, overgrown claw affects cows' weight distribution especially around the rear claw; thus, enhancing conformational changes those results to altered locomotion (Sadiq et al., 2020b; van der Tol et al., 2004). The lateral claw of the rear foot bears a larger part of the weight directed unto the limb and the function is affected when the claw length is overgrown (Alsaaod et al., 2017). Claw overgrowth affects the placement of the foot and displaces the stride during locomotion (Alsaaod et al., 2017).

Lame cows experience behavioral changes such as reduced frequency time, frequency of visits to feed bunk, and lower energy balance to compete for feed, which may result to body condition loss (Green et al., 2014; Ramanoon et al., 2018b). These behavioral changes are defensive mechanisms against the on-going pain in lame cows (Whay \& Shearer, 2017). In this study, majority of the lame cows had low BCS prior to the onset of clinical lameness. Randall et al. (2015) reported that dairy cows with low BCS were more likely to become lame in the future. The finding suggests that BCS loss occurred for certain period before the onset of gait changes. The changes in BCS as shown in this study could be used to identify cows requiring prompt management; thus, reducing the chances of future lameness event.
Cows with previous history of lameness event had higher risk of being lame in the present lactation. Although claw health records were not sufficient to identify the causes of previous lameness episodes in the enrolled cows, other related studies have shown that cows with previous lameness history are more likely to be lame in subsequent lactation (Huxley et al., 2013; Randall et al., 2015). Such relapses in lameness event are common in CHL due to pathological changes within the capsule that destabilizes the pedal bone (Newsome et al., 2017b; Räber et al., 2006). Moreover, most of the studied cows underwent routine CT once before enrollment and no further trimming was conducted during the study period. Repeated CT might be required improve the stability of pedal bone and reduce the tendency of relapse of previous horn lesions (Sadiq et al., 2020b). Preventive claw trimming at dry off and again at DIM 40-60 could reduce the lameness prevalence during early lactation (Green et al., 2002).

Factors such as HCS, leg hygiene, and parity were not associated with lameness incidence in the present study. In crosssectional studies, higher odds of lameness were observed in cows with poor HCS (swollen hock or hair loss) (Solano et al., 2015), higher parity (Lim et al., 2015; Machado et al., 2010) and poor leg hygiene (Relun et al., 2013; Sadiq et al., 2017a). However, the direction of the events could not be determined in these studies. All the sampled cows in the present study had normal HCS during enrollment and majority of the lame cows had no changes in their 
hock condition during their first lameness events. This finding reinstates that clawrelated changes were more important in influencing lameness occurrence in the studied cows than hock injuries. The lack of association between lameness, parity, leg hygiene, and BDI could be related to the various causes of lameness and their severity in the sampled cows. Moreover, studies have shown that parity influences the occurrence of infectious claw lesions and CHLs in different ways. Cows at higher parity had higher incidence of CHL at drying off (Machado et al., 2010) and during lactation (Oberbauer et al., 2013). In contrast, the risk of DD was lower in greater parity cows compared with those at first and second parity (Holzhauer et al., 2006), whereas incidence of DD was twice in heifers that calved at younger age compared to those that calved at older age (Mellado et al., 2018).

Herd cleanliness is another factor associated with lameness risk in dairy herds. The overall herd cleanliness can be estimated using the leg hygiene of individual cows (Cook, 2006). Herein, we found no association between lameness risk and leg hygiene at cow level. This finding contradicts those of previous studies where poor leg hygiene increased the chances of lameness and infectious claw lesions in dairy cows (Solano et al., 2015, 2016). However, one of the study designs was cross-sectional and thus; limits further information on the events' direction. Since the present study entailed a longitudinal approach, the result suggests that leg hygiene may not be as important as other welfare parameters influencing lameness incidence during lactation. However, the subjectivity of the leg hygiene scoring method and lesions prevalence could also contribute to the disparity in results. Majority of the claw lesions observed in this study were CHL, and leg hygiene may play more significant role in the development of claw lesions of infectious origin (Relun et al. 2013; WilsonWelder et al., 2015).

\section{Claw Lesions Analysis}

A total of 57 claw lesions were recorded in $37 \%(44 / 120)$ of the enrolled cows during the study. Thirty-nine cows $(68.4 \%)$ were lame amongst the cows affected with claw lesions. CHL were predominant $(75.4 \%$; $43 / 57)$ compared to ICL $(24.7 \% ; 14 / 57)$ (Table 4).

The proportion of lame cows amongst each lesion category was highest for sole lesions (SU/SH) $(16 / 20 ; 80 \%)$ and ICL (12/14; 86\%) (Figure 2).

The lesion prevalence is comparable to the reports in previous studies (Becker et al., 2014; Cramer et al., 2008). Regarding the higher prevalence of CHL compared to infectious types, our previous study in selected dairy farms in Selangor showed a similar result, with sole lesions and WLD being the most prevalent at cow level (Sadiq et al. 2017a). CHL are multifactorial and intensive dairy facilities are highly susceptible to claw disorders (Cook et al., 2016; Charfeddine \& Perez-Cabal, 2017). Preventive measures entail appropriate stall designs to improve cow comfort, as 
Table 4

Prevalence of claw lesions at during lactation of 120 cows enrolled in the study by categories of claw lesions and proportion of lame cows

\begin{tabular}{lcc}
\hline & Claw lesions & Lame cows \\
\hline Claw horn lesions & & 16 \\
SL & 20 & 5 \\
WLD & 10 & 4 \\
TU & 5 & 1 \\
HU & 1 & 1 \\
Others & 7 & $27(62.7)$ \\
\hline Total $^{1}(\%)$ & $43(75.4)$ & $12(85.7)$ \\
\hline ICL $^{2}$ & $14(24.6)$ & $39(68.4)$ \\
\hline Total $^{4}($ Overall $)$ & $57(100)$ & \\
\hline
\end{tabular}

Note.

${ }^{1}$ Total number and percentage of claw horn lesions

${ }^{2}$ Infectious claw lesions comprise of digital and interdigital dermatitis, heel horn erosion, and swollen coronet ${ }^{3}$ Others comprise of corkscrew claw, interdigital hyperplasia

${ }^{4}$ Total number of claw lesions recorded in both groups

Cows were counted more than one if they had more than one claw lesion

$\mathrm{ICL}=$ infectious claw lesion, $\mathrm{SL}=$ sole lesions, $\mathrm{WLD}=$ white line disease, $\mathrm{TU}=$ toe ulcers, $\mathrm{HU}=$ heel ulcer

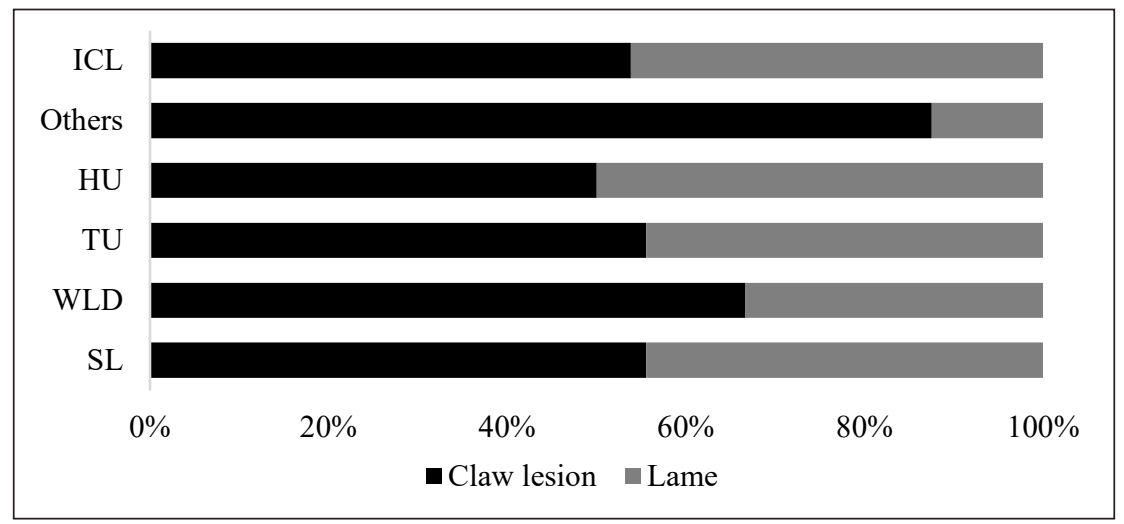

Figure 2. Proportion of lame cows among those affected with various claw lesions

well as specific management during high risk period. For instance, the cows were housed under completely confined systems without provision for pasture grazing. Recent reports suggest that pasture access is important for the reduction of CHL occurrence (Armbrecht et al., 2018) and these lesions elicit greater pain than other foot lesions based on the evaluation of nociceptive threshold (Passos et al., 2017). An indication of such event in this study was the higher record of lameness cases amongst those affected with CHL.

Covariates in the univariable model were median BCS and PLE. Cows with poor $\mathrm{BCS}(<3.0)(\mathrm{OR}=5.7$; 95\% CI 1.6-20.4) 
and PLE (OR $=7.27 ; 95 \% \mathrm{CI}=2.1-24.7)$ had higher lameness prevalence in relation to those good BCS and no lameness history. At the multivariable level, the chances of having CHL tended to be associated with lower BCS $(p=0.08)$, whereas higher odds of $\mathrm{CHL}(\mathrm{OR}=5.4 ; 95 \%$ CI 2.4-23.3) was observed in cows with PLE (Table 5).

The finding regarding association between BCS and CHL is consistent with recent studies reporting significant $\mathrm{BCS}$ loss before (Sepúlveda-Varas et al., 2018; Stambuk et al., 2019) and after (SepúlvedaVaras et al., 2018) CHL incidence. Various changes occurring around calving that induces body condition loss has been linked to the increased risk of CHL (Bicalho et al., 2009; Machado et al., 2010; Newsome et al., 2017a). Thickness of DC; a protective apparatus for the sensitive structures during limb loading, is reduced during body condition loss (Räber et al., 2006; Bicalho et al., 2009). Hence, thinner cows in the present study might be developed thinner DC; thus, reducing the protective function and increasing the chance of corium injury. Newsome et al. (2017b) showed that thinness of the DC, corium (soft tissues), and back fat thickness increased the likelihood of CHL lameness. However, CHL occurred independent of both parameters, indicating that thinness of the DC could result from other physiological changes (aside body fats) affecting the suspensory apparatus (Newsome et al., 2017b).

Cows in the present study had positive association between PLE and CHL prevalence. The result is in agreement with that of Randall et al. (2015), where severe WLD and sole lesions were associated with increased risk of future lameness events. Likewise, Foditsch et al. (2016) demonstrated that cows affected with CHL in the previous lactation and those lame at drying off had greater risk of developing CHDL in the subsequent lactation. These events could be due to pathological changes in the claw capsule resulting from similar lesion type during previous lactations. The relapse of such lesions in subsequent lactation was mostly reported during the high risk period for lameness (Foditsch et al., 2016). For instance, the claw affected with CHDL had significant bone development that majorly influences the locomotion score in the future (Newsome et al., 2016). Our finding supports the suggestion linking lifetime lameness history and future risk of CHL.

Both overgrown claw and BDI were not associated with CHL. The different floor designs and herd cleanliness might contribute to such finding, since these factors mediate the growth and wear of hoof horn tissues (Alsaaod et al., 2017). Moreover, normal claw length was considered as a criterion for cow enrollment. BDI frequently results from poor stall designs and lying surfaces that are unfavorable to cow welfare (Cook et al., 2016). The lack of association between BDI and CHL prevalence could be the low severity of horn lesions and similarity in stall designs in the studied farms. Severity of lesions might not be sufficient to induce prolonged lying down time and onset of BDI. Likewise, factors 
Mohammed Babatunde Sadiq, Siti Zubaidah Ramanoon, Wan Mastura Shaik Mossadeq, Rozaihan Mansor and Sharifah Salmah Syed-Hussain

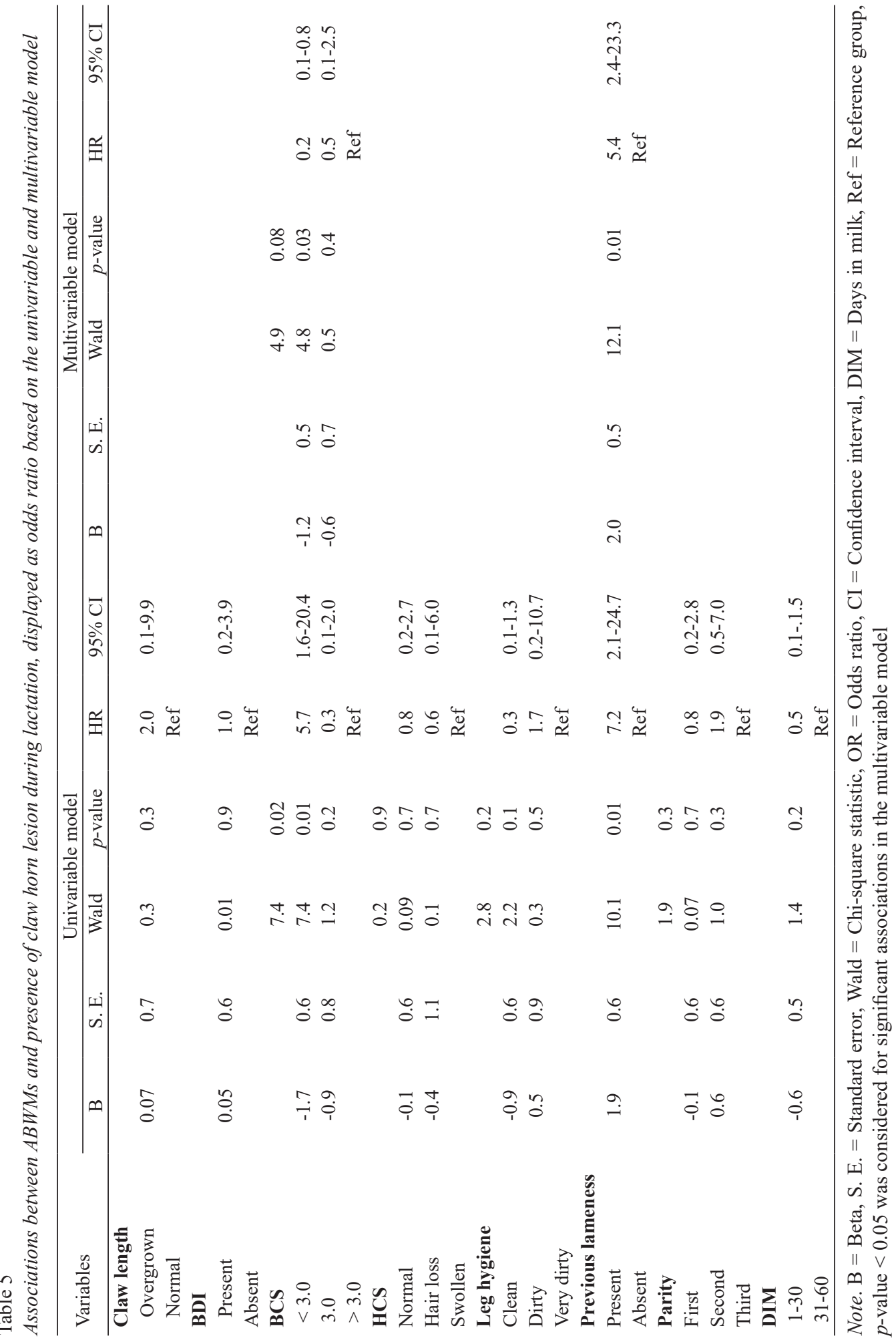


relating to stall designs differ in their impact on CHL and BDI in dairy herds (Adams et al., 2017; Cook et al., 2016).

Limitations inherent in this study are well identified. The findings in this study are specific to cows kept in free-stalls with no access to outdoor grazing. The management system was selected based on reports of increased risk of lameness and claw pathologies in confined cows. Though the analysis was carried out at cow level, a larger sample size might have provided higher chances of obtaining significant associations between lameness and other explanatory variables. Other factors such as herd hygiene and handling of the animals by farm staff might influence some of the findings, despite selecting the farms based on similar management routines and practices. Longer observational period and inclusion of other vital ABWMs for further elucidation of factors associated with lameness occurrence could be considered in future studies.

\section{ACKNOWLEDGEMENT}

This study was supported by the Universiti Putra Malaysia (UPM/8003/3/1/GP-IPS/2016/9507600). Our sincere appreciation goes to the Department of Veterinary Services (DVS), Selangor and all the technical staff of the Department of Farm and Exotic Animals Medicine and Surgery, Faculty of Veterinary Medicine UPM Serdang Selangor, Malaysia.

\section{COMPLIANCE WITH ETHICAL STANDARDS}

\section{Conflict of Interest}

The authors declare that they have no conflict of interest.

\section{Ethical Statement}

This study was approved by the Institution of Animal Care and Use Committee (UPM/ IACUC/AUP-R028/2017). Examination of the animals was conducted by trained professionals in lameness assessment and diagnosis. All the participating farmers were informed about the purpose and methods in the study and participation was voluntary.

\section{REFERENCES}

Adams, A. E., Lombard, J. E., Fossler, C. P., Román-Muñiz, I. N., \& Kopral, C. A. (2017). Associations between housing and management practices and the prevalence of lameness, hock lesions, and thin cows on US dairy operations. Journal of Dairy Science, 100(3), 2119-2136. https://doi.org/10.3168/jds.2016-11517

Alsaaod, M., Huber, S., Beer, G., Kohler, P., Schupbach-Regula, G., \& Steiner, A. (2017). Locomotion characteristics of dairy cows walking on pasture and the effect of artificial flooring systems on locomotion comfort. Journal of Dairy Science, 100(10), 8330-8337. https:// doi.org/10.3168/jds.2017-12760

Armbrecht, L., Lambertz, C., Albers, D., \& Gauly, M. (2018). Does access to pasture affect claw condition and health in dairy cows?. The Veterinary Record, 182(3), 79. https://doi. org/10.1136/vr.104554

Becker, J., Steiner, A., Kohler, S., Koller-Bahler, A., Wuthrich, M., \& Reist M. (2014). Lameness and foot lesions in Swiss dairy cows: II. Risk factors. 
Schweiz Arch Tierheilkd, 156(2), 79-89. https:// doi.org/10.1024/0036-7281/a000554

Bicalho, R. C., Machado, V. S., \& Caixeta, L. S. (2009). Lameness in dairy cattle: A debilitating disease or a disease of debilitated cattle? A cross-sectional study of lameness prevalence and thickness of the digital cushion. Journal of Dairy Science, 92(7), 3175-84. https://doi.org/10.3168/ jds.2008-1827

Bran, J. A., Daros, R. R., von Keyserlingk, M. A. G., LeBlanc, S. J., \& Hötzel, M. J. (2018). Cow and herd-level factors associated with lameness in small-scale grazing dairy herds in Brazil. Preventive Veterinary Medicine, 151(1), 79-86. https://doi.org/10.1016/j.prevetmed.2018.01.006

Bryan, M., Tacoma, H., \& Hoekstra, F. (2012). The effect of hindclaw height differential and subsequent trimming on lameness in large dairy cattle herds in Canterbury, New Zealand. New Zealand Veterinary Journal, 60(6), 349-55. https://doi.org/10.1080/00480169.2012.698443

Charfeddine, N., \& Perez-Cabal, M. A. (2017). Effect of claw disorders on milk production, fertility, and longevity, and their economic impact in Spanish Holstein cows. Journal of Dairy Science, 100(1), 653-665. https://doi. org/10.3168/jds.2016-11434

Cook, N. B. (2006). Footbath alternatives. http:// www.milkproduction.com/Library/Scientificarticles/Animal-health/Footbath-alternatives/

Cook, N. B., Hess, J. P., Foy, M. R., Bennett, T. B., \& Brotzman, R. L. (2016). Management characteristics, lameness, and body injuries of dairy cattle housed in high-performance dairy herds in Wisconsin. Journal of Dairy Science, 99(7), 5879-5891. https://doi.org/10.3168/ jds.2016-10956

Cramer, G., Lissemore, K. D., Guard, C. L., Leslie, K. E., \& Kelton, D. F. (2008). Herd- and cow-level prevalence of foot lesions in Ontario dairy cattle.
Journal of Dairy Science, 91(10), 3888-3895. https://doi.org/10.3168/jds.2008-1135

DairyCo. (n. d.). DairyCo mobility score. https:// www.farmhealthonline.com/wp-content/ uploads/2013/11/dairy_co_mobility_score.pdf

Egger-Danner, C., Nielsen, P., Fiedler, A., Müller, K., Fjeldaas, T., Döpfer, D., Daniel, V., Bergsten, C., Cramer, G., Christen, A.M., Stock, K. F., Thomas, G., Holzhauer, M., Steiner, A., Clarke, J., Capion, N., Charfeddine, N., Pryce, J. E., Oakes, E., Burgstaller, J., Heringstad, B., Ødegård, C., \& Kofler, J. (2015). ICAR claw health atlas. http://www.icar.org/Documents/ ICAR_Claw_Health_Atlas.pdf

Elanco Animal Health. (1997). Body condition scoring in dairy cattle. https://www.vet.cornell. edu/sites/default/files/1e_Elanco $\% 20$ Cow $\% 20$ Body_condition_scoring_V3.pdf

Foditsch, C., Oikonomou, G., Machado, V. S., Bicalho, M. L., Ganda, E. K., Lima, S. F., \& Bicalho, R. C. (2016). Lameness prevalence and risk factors in large dairy farms in upstate New York. Model development for the prediction of claw horn disruption lesions. PLOS One, 11(1), e0146718. https://doi.org/10.1371/journal. pone. 0146718

Gibbons, J., Vassuer, E., Rushen, J., \& de Passillé, A. M. (2012). A training programme to ensure high repeatability of injury scoring of dairy cows. Animal Welfare, 21(3), 379-388. https:// doi.org/10.7120/09627286.21.3.379

Green, L. E., Hedges, V. J., Schukken, Y. H., Blowey, R. W., \& Packington, A. J. (2002). The impact of clinical lameness on the milk yield of dairy cows. Journal of Dairy Science, 85(9), 2250-2256. https://doi.org/10.3168/jds.S00220302(02)74304-X

Green, L. E., Huxley, J. N., Banks, C., \& Green, M. J. (2014). Temporal associations between low body condition, lameness and milk yield in a 
UK dairy herd. Preventive Veterinary Medicine, 113(1), 63-71. https://doi.org/10.1016/j. prevetmed.2013.10.009

Holzhauer, M., Hardenberg, C., Bartels, C. J., Frankena, K. (2006). Herd- and cow-level prevalence of digital dermatitis in the Netherlands and associated risk factors. Journal of Dairy Science, 89(2), 580-588. https://doi.org/10.3168/ jds.S0022-0302(06)72121-X

Hund, A., Logrono, J. C., Ollhort, R. D., \& Kofler, J. (2019). Aspects of lameness in pasture based dairy farms. Veterinary Journal, 244, 83-90. https://doi.org/10.1016/j.tvj1.2018.12.011

Huxley, J. N. (2013). Impact of lameness and claw lesions on health and production. Livestock Science, 156(1-3), 64-70. https://doi. org/10.1016/j.livsci.2013.06.012

Lim, P. Y., Huxley, J. N., Willshire, J. A., Green, M. J., Othman, A. R., \& Kaler, J. (2015). Unravelling the temporal association between lameness and body condition score in dairy cattle using a multistate modelling approach. Preventive Veterinary Medicine, 118(4), 370-377. https:// doi.org/10.1016/j.prevetmed.2014.12.015

Machado V. S., Caixeta L. S., McArt J. A. A., \& Bicalho R. C. (2010). The effect of claw horn disruption lesions and body condition score at dry-off on survivability, reproductive performance, and milk production in the subsequent lactation. Journal of Dairy Science, 93(9), 4071-4078. https://doi: 10.3168/jds.2010-3177

Mellado, M., Saavedra, E., Gaytán, L., Véliz, F., Macías-Cruz, U., Avendaño-Reyes, L., García, J. (2018). The effect of lameness-causing lesions on milk yield and fertility of primiparous Holstein cows in a hot environment. Livestock Science, 217, 8-14. https://doi.org/10.1016/j. livsci.2018.09.008

Newsome, R. F., Green, M. J., Bell, N. J., Bollard, N. J., Mason, C. S., Whay, H. R., \& Huxley,
J. N. (2017a). A prospective cohort study of digital cushion and corium thickness. Part 1: Associations with body condition, lesion incidence, and proximity to calving. Journal of Dairy Science, 100(6), 4745-4758. https://doi. org/10.3168/jds.2016-12012

Newsome, R. F., Green, M. J., Bell, N. J., Bollard, N. J., Mason, C. S., Whay, H. R. \& Huxley, J. N. (2017b). A prospective cohort study of digital cushion and corium thickness. Part 2: Does thinning of the digital cushion and corium lead to lameness and claw horn disruption lesions?. Journal of Dairy Science, 100(6), 4759-4771. https://doi.org/10.3168/jds.2016-12013

Newsome, R., Green, M. J., Bell, N. J., Chagunda, M. G. G., Mason, C. S., Rutland, C. S., Sturrock, C. J., Whay, H. R., \& Huxley, J. N. (2016). Linking bone development on the caudal aspect of the distal phalanx with lameness during life. Journal of Dairy Science, 99(6), 4512-4525. https://doi. org/10.3168/jds.2015-10202

Nuss, K., \& Paulus, N. (2006). Measurements of claw dimensions in cows before and after functional trimming: A post-mortem study. Veterinary Journal, 172(2), 284-292. https://doi. org/10.1016/j.tvj1.2005.04.031

Oberbauer, A. M., Berry, S. L., Belanger, J. M., McGoldrick, R. M., Pinos-Rodriquez, J. M., \& Famula, T. R. (2013). Determining the heritable component of dairy cattle foot lesions. Journal of Dairy Science, 96(1), 605-613. https://doi. org/10.3168/jds.2012-5485

Olechnowicz, J., Jedrzej, M., \& Jaskowski, J. M. (2010). Impact of clinical lameness, calving season, parity, and month of lactation on milk, fat, protein, and lactose yields during early lactation of dairy cows. Bulletin of the Veterinary Institute in Pulawy, 54(4), 605-610.

Oliveira, V. H. S., Sørensen, J. T., \& Thomsen, P. T. (2017). Associations between biosecurity practices and bovine digital dermatitis in Danish 
dairy herds. Journal of Dairy Science, 100(10), 8398-8408. https://doi.org/10.3168/jds.201712815

Passos, L. T., da Cruz, E. A., Fischer, V., da Porciuncula, G. C., Werncke, D., Dalto, A. G. C., Stumpf, M. T., Vizzotto, E. F., \& da Silveira, I. D. B. (2017). Dairy cows change locomotion score and sensitivity to pain with trimming and infectious or non-infectious lesions. Tropical Animal Health and Production, 49(4), 851-856. https://doi.org/10.1007/s11250-017-1273-0

Räber, M., Scheeder, M. R., Ossent, P., Lischer, C. J., \& Geyer, H. (2006). The content and composition of lipids in the digital cushion of the bovine claw with respect to age and location - A preliminary report. The Veterinary Journal, 172(1), 173-177. https://doi.org/10.1016/j.tvj1.2005.03.009

Ramanoon, S. Z., Sadiq, M. B., Abdul Razak, N. M., Shaik Mossadeq, W. M., Mansor, R., \& SyedHussain, S. S. (2018a). Retrospective analysis of lameness cases in cattle reported to the University Veterinary Hospital, University Putra Malaysia, from 2013-2017. Jurnal Veterinar Malaysia, 30(1), 1-6.

Ramanoon, S. Z., Sadiq, M. B., Shaik Mossadeq, W. M., Mansor, R., \& Syed-Hussain, S. S. (2018b). The impact of lameness on dairy cattle welfare: Growing need for objective methods of detecting lame cows and assessment of associated pain. https:/www.intechopen.com/ books/animal-welfare/the-impact-of-lamenesson-dairy-cattle-welfare-growing-need-forobjective-methods-of-detecting-lame-

Randall, L. V., Green, M. J., Chagunda, M. G., Mason, C., Archer, S. C., Green, L. E., \& Huxley, J. N. (2015). Low body condition predisposes cattle to lameness: An 8-year study of one dairy herd. Journal of Dairy Science, 98(6), 3766-3777. https://doi.org/10.3168/jds.2014-8863

Relun, A., Lehebel, A., Chesnin, A., Guatteo, R., \& Bareille, N. (2013). Association between digital dermatitis lesions and test-day milk yield of Holstein cows from 41 French dairy farms. Journal of Dairy Science, 96(4), 2190-2200. https://doi.org/10.3168/jds.2012-5934

Robichaud, M. V., Rushen, J., de Passillé, A. M., Vasseur, E., Orsel, K., \& Pellerin, D. (2019). Associations between on-farm animal welfare indicators and productivity and profitability on Canadian dairies: I. On freestall farms. Journal of Dairy Science, 102(5), 4341-4351. https://doi. org/10.3168/jds.2018-14817

Sadiq M. B., Ramanoon, S. Z., Shaik Mossadeq, W. M., Mansor, R., \& Syed-Hussain, S. S. (2020a). Cowand herd-level factors associated with lameness in dairy farms in Peninsular Malaysia. Preventive Veterinary Medicine, 184, 105163. https://doi. org/10.1016/j.prevetmed.2020.105163

Sadiq M. B., Ramanoon, S. Z., Shaik Mossadeq, W. M., Mansor, R., Syed-Hussain, S. S. (2021). Prevalence and risk factors for hoof lesions in dairy cows in Peninsular Malaysia. Livestock Science, 245, 104404. https://doi.org/10.1016/j. livsci.2021.104404

Sadiq, M. B., Ramanoon, S. Z., Mansor, R., SyedHussain, S. S., \& Shaik Mossadeq, W. M. (2017a). Prevalence of lameness, claw lesions, and associated risk factors in dairy farms in Selangor, Malaysia. Tropical Animal Health and Production, 49(8), 1741-1748. https://doi: $10.1007 / \mathrm{s} 11250-017-1387-4$

Sadiq, M. B., Ramanoon, S. Z., Mansor, R., SyedHussain, S. S., \& Shaik Mossadeq, W. M. (2017b). Association between lameness and indicators of dairy cow welfare based on locomotion scoring, body and hock condition, leg hygiene and lying behavior. Animals (Basel), 7(11), 79. https://doi: 10.3390/ani7110079

Sadiq, M. B., Ramanoon, S. Z., Shaik Mossadeq, W. M., Mansor, R., \& Syed-Hussain, S. S. (2020b). Claw trimming as a lameness management practice and the association with welfare and 
production in dairy cows. Animals, 10(9), 1515. https://doi.org/10.3390/ani10091515

Sadiq, M. B., Ramanoon, S. Z., Shaik Mossadeq, W. M., Mansor, R., \& Syed-Hussain, S. S. (2019). Dairy farmers' perceptions of and actions in relation to lameness management. Animals, 9(5), 270. https://doi: 10.3390/ani9050270

Sepúlveda-Varas, P., Lomb, J., von Keyserlingk, M. A. G., Held, R., Bustamante, H., \& Tadich, N. (2018). Claw horn lesions in mid-lactation primiparous dairy cows under pasture-based systems: Association with behavioral and metabolic changes around calving. Journal of Dairy Science, 101(10), 1-12. https://doi. org/10.3168/jds.2018-14674

Solano, L., Barkema, H. W., Mason, S., Pajor, E. A., LeBlanc, S. J., \& Orsel, K. (2016). Prevalence and distribution of foot lesions in dairy cattle in Alberta Canada. Journal of Dairy Science, 99(8), 6828-6841. https://doi.org/10.3168/ jds.2016-10941

Solano, L., Barkema, H. W., Pajor, E. A., Mason, S., LeBlanc, S. J., Zaffino Heyerhoff, J. C., Nash, C. G., Haley, D. B., Vasseur, E., Pellerin, D., Rushen, J., de Passille, A. M., \& Orsel, K. (2015). Prevalence of lameness and associated risk factors in Canadian Holstein-Friesian cows housed in freestall barns. Journal of Dairy Science, 98(10), 6978-6991. https://doi. org/10.3168/jds.2015-9652
Stambuk, C. R., McArt, J. A. A., Bicalho, R. C., Miles, A. M., \& Huson, H. J. (2019). A longitudinal study of digital cushion thickness and its function as a predictor for compromised locomotion and hoof lesions in Holstein cows. Translational Animal Science, 3(1), 74-83. https://doi.org/10.1093/tas/txy107

Thomas, H. J., Remnant, J. G., Bollard, N. J., Burrows, A., Whay, H. R., Bell, N. J., Mason, C., \& Huxley, J. N. (2016). Recovery of chronically lame dairy cows following treatment for claw horn lesions: A randomised controlled trial. Veterinary Record, 178(5), 116. http://dx.doi. org/10.1136/vr.103394

van der Tol, P. P., van der Beek, S. S., Metz, J. H., Noordhuizen-Stassen, E. N., Back, W., Braam, C. R., \& Weijs, W. A. (2004). The effect of preventive trimming on weight bearing and force balance on the claws of dairy cattle. Journal of Dairy Science, 87(6), 1732-1738. https://doi. org/10.3168/jds.S0022-0302(04)73327-5

Whay, H. R., \& Shearer, J. K. (2017). The impact of lameness on welfare of the dairy cow. Veterinary Clinics of North America: Food Animal Practice, 33(2), 153-64. https://doi. org/10.1016/j.cvfa.2017.02.008

Wilson-Welder, J. H., Alt, D. P., \& Nally, J. E. (2015). Digital dermatitis in cattle: Current bacterial and immunological findings. Animals (Basel), 5(4), 1114-1135. https://doi.org/10.3390/ani5040400 
